\title{
Family Characteristics and Parenting Quality in Relation to at Home Secondhand Smoking Exposure on Infants
}

\author{
Leny Latifah $^{1}$, Arif Musoddaq ${ }^{1}$, Yusi Dwi Nurcahyani ${ }^{1}$, Diah Yunitawati', Marizka Khairunnisa ${ }^{1}$ \\ ${ }^{1}$ Researcher, Magelang Unit of Health Research and Development, National Institute of Health Research and \\ Development, Ministry of Health, Indonesia
}

\begin{abstract}
Secondhand Smoking (SHS) exposure had a great impact on health, especially among a vulnerable group like breastfeeding mothers and infants. No previous research was found on the risk of lower parenting quality with the risk of SHS exposure among infants. This research aimed to analyze the prevalence of SHS exposure at home in infants with family characteristics and parenting quality. A cross-sectional study was conducted in Magelang with 216 households that had an infant as a household member. SHS exposure at home and family characteristics assessed with a questionnaire and parenting quality assessed with HOMESF, divided into emotional support and cognitive stimulation. The prevalence of SHS at home was $81 \%$. Family characteristics related were higher means of sum of children $(t=-2.494 ; p=0.013)$, shorter birth spacing $(t=-3.146 ; p=0.002)$, younger age of mother $(t=-3.798 ; p=0.000)$ and father $(t=-3.766 ; p=0.000)$, and shorter years of father education $(\mathrm{t}=-2.933 ; \mathrm{p}=0.004)$ were significantly related to higher prevalence of SHS exposure at home.and also lower cognitive stimulation $(\mathrm{F}=2.705-\mathrm{p}=0.046)$. Several family characteristics and also the quality of parenting identified as factors associated with infant SHS exposure at home. The high prevalence needs attention for intensive health promotion and consistent implementation of smoke-free legislation to protect infant and breastfeeding mothers from SHS exposure at home.
\end{abstract}

Keywords: secondhand smoking; infants; breastfeeding mother; parenting quality

\section{Introduction}

Exposure to secondhand smoke (SHS) responsible for estimated 600.000 death per year worldwide. Children make up over a quarter of all deaths and half of all disability-adjusted life years associated with SHS exposure $^{1,2}$. Exposure to SHS, also known as passive smoking or environmental tobacco smoke, is the unintentional inhalation of cigarette smoke from other person ${ }^{2}$. Secondhand smoke exposure has been proved to be associated with health risks and death ${ }^{3}$. Exposure to cigarette smoke in pregnant women is associated with an increased risk of miscarriage, LBW, and asthma in babies $^{4,5}$.

There is still limited scientific literature at SHS articles focusing on younger children, most were done in older children or adolescents ${ }^{6}$.Infants can be more vulnerable to the exposure risks, especially SHS exposure at home, the place where infants are more exposed to SHS than in other places because they spendmoretimeathome ${ }^{7}$. The relation between parenting and the risk for SHS exposure were not clearly described, and no previous study among infant was found. Previous researches on parenting concerning SHS were mostly focused on parenting style and smoking behavior of their children ${ }^{8}$. To fill this gap, this research aimed to analyze the prevalence of SHS exposure at home in breastfeeding mothers and their infants with family characteristics and parenting quality.

\section{Method}

This paper is part of a study on the growth and development of children in replete and non-replete areas of IDD in Magelang Central Java, the main topic was presented in the 2019 Asian Congress of Nutrition analyzing the relation between breastmilk iodine level and infant development in replete and non-replete areas $^{9}$.This article focused on the problem of at home 
secondhand smoke exposure on infants and breastfeeding mothers.

This was a cross-sectional study conducted in Magelang, Central Java, with 213 households which had infants and breastfeeding mothers as a household member. Breastfeeding mothers who participate in this study were the same as the study on iodine sufficiency among pregnant women in the previous years. Simple random sampling was used to determine the participants of the research ${ }^{10}$. The sampling frame for this study was 244 mothers which complete the earlier year study andcomplete the pregnancy until having babies, and 213 of them complete this study.

SHS exposure at home and family characteristics assessed with questionnaire and parenting quality assessed with HOME-SF. Interviews were conducted with the mothers. Demographic data had collected on paternal and maternal age and education years, length of the marriage, a sum of children, and child's birth order.SHS questionnaire including a question about the presence of at home SHS exposure, and the frequency of SHS exposure at home.
The quality of the caregiving environment was measured using the HOME Inventory Short Form (HOME-SF) model consisting of 20 items. Data obtained using interviews and direct observation of the interaction between mother and child. The parenting quality refers to the extent to which the environment provides physical stimulation through sensory input, and emotional stimulation provided through the bond of affection between caregivers and children. The HOMESF scale has two answer choices, yes (score 1) and no (score 0 ). Measurement of the quality of the caregiving environment is done by adding up the scores contained in the HOME-SF questionnaire ${ }^{11}$. In this study, we further analyzed the quality of parenting, adopted the analysis from the NLSY79 child study ${ }^{12}$, which further explore HOME-SF into two subscales of cognitive stimulation and emotional support.

Data analysis was performed with an independent t-test and oneway Anova to explore the relation between family characteristics, parenting quality.

\section{Result}

Table 1. Family Characteristics Based on at Home SHS Exposure

\begin{tabular}{|c|c|c|c|c|}
\hline \multirow[b]{2}{*}{ Variables } & \multicolumn{4}{|c|}{ At home SHS } \\
\hline & $\begin{array}{c}\text { Non-Exposure } \\
\text { n=41(19.0\%) } \\
\text { Means (SD) }\end{array}$ & $\begin{array}{c}\text { Exposure } \\
\text { n=175(81.0\%) } \\
\text { Means (SD) }\end{array}$ & $\mathbf{t}$ & $\mathbf{p}$ \\
\hline Sum of children & $2.22(0.91)$ & $1.87(0.77)$ & -2.494 & $0.013 *$ \\
\hline Child birth's spacing & $6.50(5.07)$ & $4.18(3.76)$ & -3.146 & $0.002 *$ \\
\hline Paternal age & $37.05(6.27)$ & $32.95(6.26)$ & -3.766 & $0.000 *$ \\
\hline Maternal age & $32.24(5.21)$ & $28.41(5.94)$ & -3.798 & $0.000 *$ \\
\hline Paternal length of education & $10.80(3.44)$ & $9.31(2.80)$ & -2.933 & $0.004 *$ \\
\hline Maternal length of education & $10.63(3.85)$ & $9.87(2.64)$ & -1.513 & 0.132 \\
\hline Paternal age when married & $27.74(4.21)$ & $26.58(5.19)$ & -3.766 & 0.185 \\
\hline Maternal age when married & $22.94(3.82)$ & $21.99(4.82)$ & -3.798 & 0.244 \\
\hline Length of marriage & $9.30(5.71)$ & $6.53(4.67)$ & -3.257 & $0.001 *$ \\
\hline
\end{tabular}


This research found a very high prevalence among SHS exposure at home for infant (81\%), and most of them with daily $(62 \%)$ or weekly $(12.9 \%)$ exposure. This research also found several family characteristics related to the higher prevalence of SHS exposure at home (Table 1). Higher means of sum of children ( $\mathrm{t}=$ -2.494; $\mathrm{p}=0.013)$, shorter birth spacing $(\mathrm{t}=-3.146$; $\mathrm{p}=0.002)$, younger age of mother $(\mathrm{t}=-3.798 ; \mathrm{p}=0.000)$ and father $(\mathrm{t}=-3.766 ; \mathrm{p}=0.000)$, and shorter years of father education ( $\mathrm{t}=-2.933 ; \mathrm{p}=0.004)$ were significantly related to higher prevalence of SHS exposure at home. Maternal length of education and parental age when married did not significantly relate to SHS exposure at home.

Table 2. Parenting Quality-Based at Home SHS Exposure Frequency

\begin{tabular}{|c|c|c|c|c|c|c|}
\hline \multirow{2}{*}{ Variables } & \multicolumn{5}{|c|}{ At Home SHS Exposure } \\
\cline { 2 - 7 } & $\begin{array}{c}\text { Never(n=40) } \\
\text { Means (SD) }\end{array}$ & $\begin{array}{c}\text { Monthly(n=13) } \\
\text { Means (SD) }\end{array}$ & $\begin{array}{c}\text { Weekly(n=28) } \\
\text { Means (SD) }\end{array}$ & $\begin{array}{c}\text { Daily(n=134) } \\
\text { Means (SD) }\end{array}$ & F & P \\
\hline Emotional support & $7.00(1.07)$ & $6.77(1.53)$ & $6.53(1.07)$ & $6.69(1.15)$ & 2.705 & 0.366 \\
\hline $\begin{array}{c}\text { Cognitive } \\
\text { stimulation }\end{array}$ & $5.76(1.28) \mathrm{a}$ & $6.15(1.68) \mathrm{a}$ & $5.59(1.22)$ & $5.29(1.31)$ & 1.061 & $0.046^{*}$ \\
\hline
\end{tabular}

${ }^{\text {a }}$ significantly different with daily at-home SHS exposure

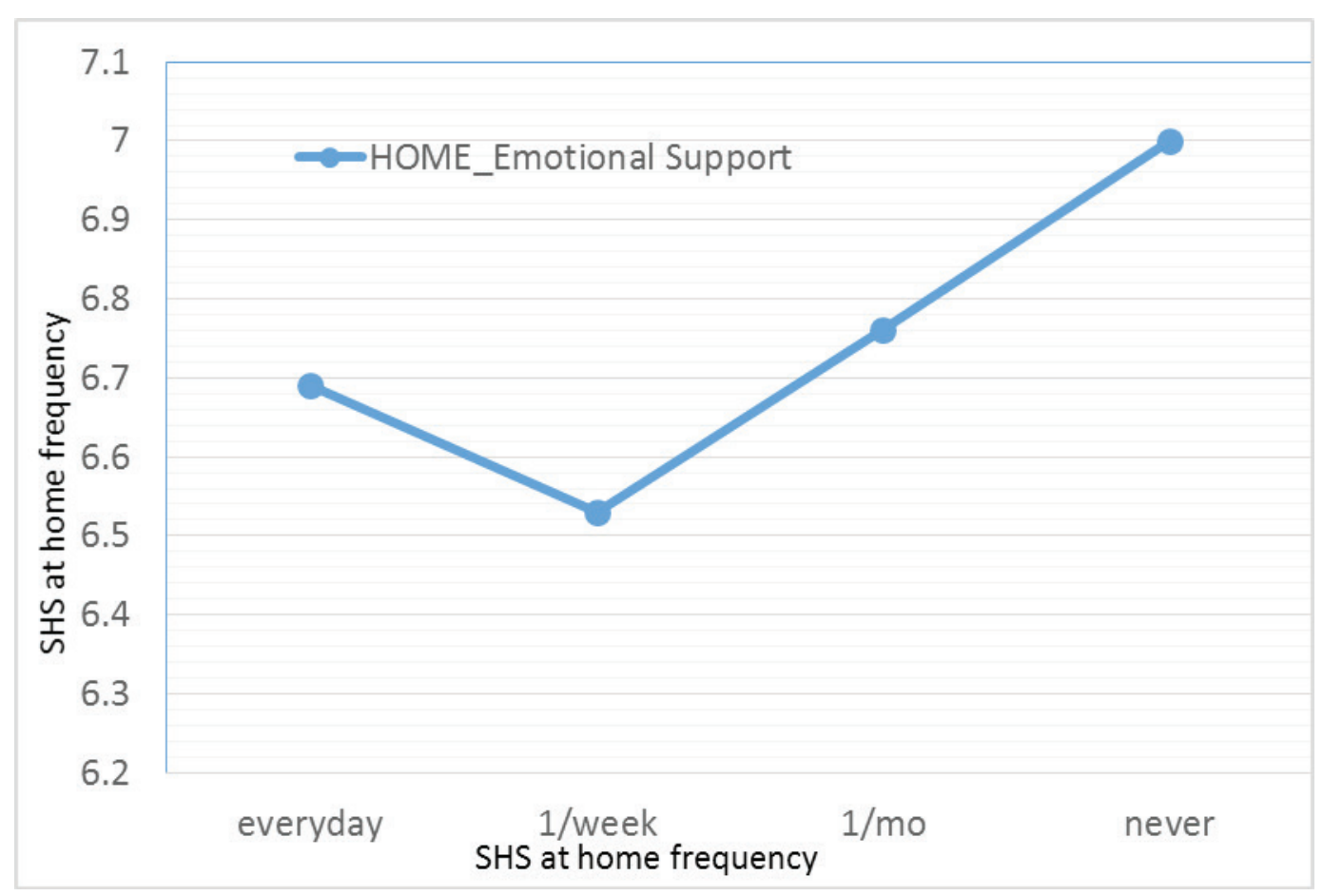

Figure 1. Relations between the frequency of at-home SHS and emotional support

Parenting quality in this research was represented by emotional support and cognitive stimulation. We analyze the difference in parenting quality with the level of SHS exposure at-home frequency, from daily, weekly, monthly, and no exposure (table 2). This research found no significant difference in emotional support with the frequency of SHS exposure at home $(\mathrm{F}=1.061 ; \mathrm{p}=0.37)$. On the other hand, cognitive stimulation, particularly daily and weekly exposure, related to significantly lower 
quality of cognitive stimulation at home $(\mathrm{F}=2.705 ; \mathrm{p}=0.046)$, and not significantly related to emotional support.

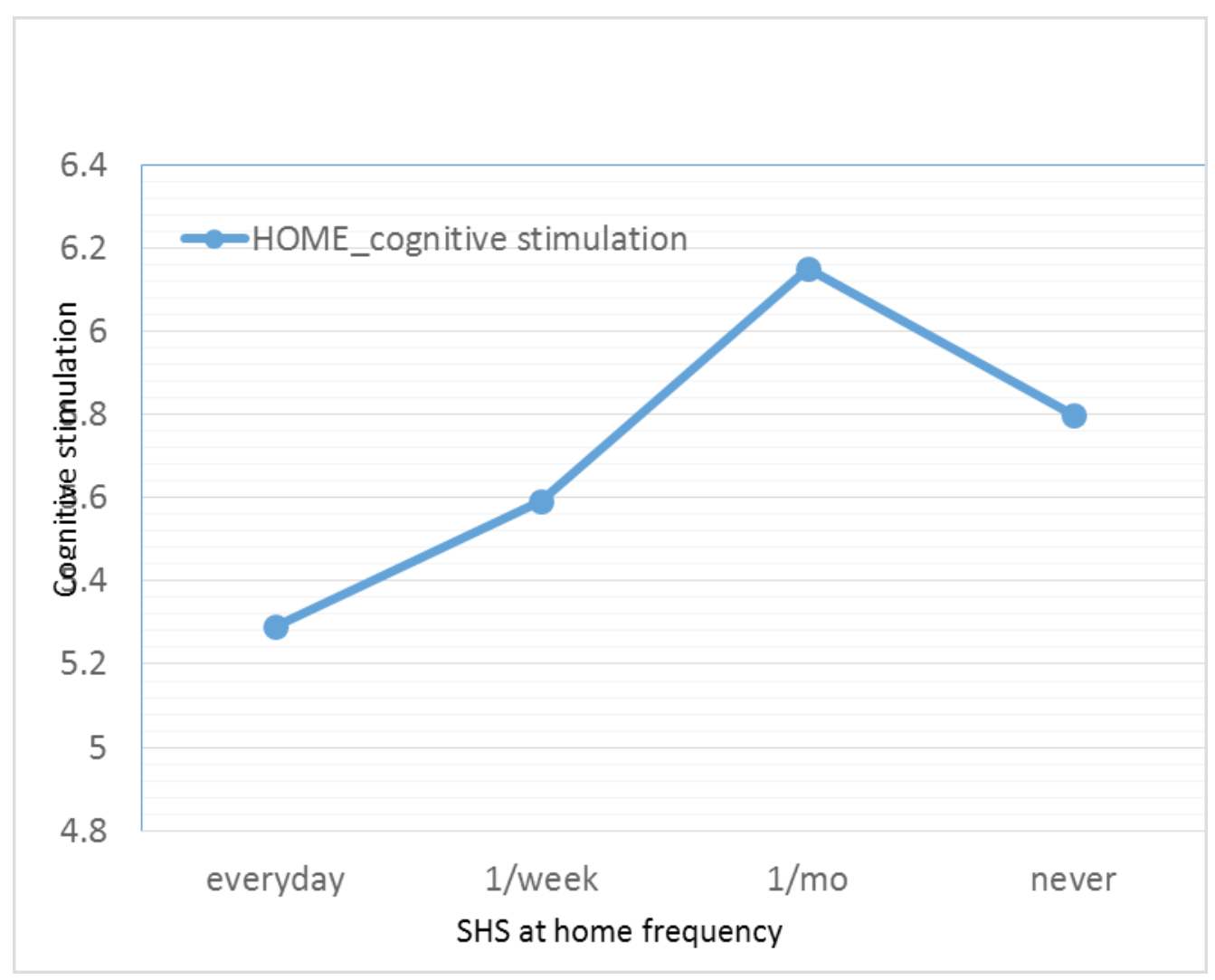

Figure 2. Relations between the frequency of at-home SHS and cognitive stimulation

\section{Discussion}

This research revealed a very high prevalence of at home SHS exposure in infants and breastfeeding mothers (80.1\%), with $63 \%$ of them being exposed daily to SHS at home. Studies in several countries showed a much lower prevalence. Research in Aleta Wondo, Ethiopia reported $22 \%$ daily smoking exposure at home ${ }^{13}$. SHS prevalence in this research was similar to nationally representative data of a higher age population in Indonesia. The SHS exposure prevalence among Indonesian adolescents (1215 years old) was $85.4 \%$, also represented the world's highest prevalence ${ }^{14}$. This fact proved that an infant presence in a household in Indonesia did not modify at home smoking behavior. The man smokers prevalence above 15 years old in Indonesia also high, 62,9\% in 2018, which also recorded as the highest prevalence for men smokers in the world ${ }^{15}$.

The high prevalence of infant exposure towards at-home SHS is similar to a research result in China, which revealed the highest prevalence of SHS exposure experienced by women and infants, where girls are at risk of being exposed to secondhand smoke 10 percent higher than boys ${ }^{16}$. Similar to the results of this study, several other studies have also shown mother education level as a significant factor affecting cigarette smoke exposure at home. Research in China shows higher maternal education, related to a lower risk of SHS exposure at home ${ }^{16}$. Research in Iran also shows similar results. Maternal and paternal education in the nonexposure SHS group was higher than in the exposure group.Exposure to cigarette smoke in nursing mothers is related to the duration of exclusive breastfeeding. Breastfeeding mothers exposed to cigarette smoke tend to stop giving exclusive breastfeeding earlier than SHS non-exposure to breastfeeding mothers. The proportion of infants exclusively breastfed in families with smoking family members was 27 percent less than familieswithout smoking family members ${ }^{17}$.In adults, women experienced more exposure to SHS at home (57.8 percent) than men (52\%). 
This research revealed some family characteristics related significantly to a higher prevalence of SHS exposure at home. Besides women, the younger age group also more had a higher level of SHS exposure. A study in Myanmar showed, younger ages group also show higher exposure to SHS, probably because they are less concerned about health problems ${ }^{18}$. This research found, the younger the parents, both mother, and father, the higher SHS exposure probabilities. A study in Spain revealed parents age 18-30 were more likelyto report SHS exposure at home ${ }^{19}$.In the future, this SHS exposure will also affect whether or not a person will decide to quit smoking easily. Research conducted in South Korea revealed that adolescents exposed to SHS every day find it more difficult to quit smoking compared with adolescents who are less or not exposed to SHS at all in the home environment ${ }^{20}$. In this study, $63 \%$ of infants exposed daily, make them at higher risk for developing smoking habit later in life.

Lower paternal education is related to a higher prevalence of SHS at home, but not maternal education. This finding is similar to a systematic review article that found a significant association between low education and increased risk of SHS exposure at home ${ }^{21}$. It is slightly different from a study in Iran, which showed that parents' education (mother and father) was higher in the non-SHS exposure group than parents' education in the SHS exposure group ${ }^{17}$.Another research from China showed maternal education played a significant factor that affected SHS exposure at home. Higher maternal education, related significantly to a lower risk of SHS exposure in children ${ }^{16}$.

This research found a higher risk of SHS related to a lower social status like parental education. SHS exposure at home also higher in the more vulnerable family. The characteristics are family with a higher sum of children, a shorter birth spacing, and also a lower cognitive stimulation. A higher SHS level at home in younger maternal and paternal age also reflected still lack of awareness among younger people about the hazard in SHS at home exposure. It more prevalent specifically among susceptible persons like infants and breastfeeding mothers. It also reflects the tendency to increase the numbers of smokers and SHS in Indonesia. Successful experience from many countries in decreasing prevalence of SHS due to strengthening the comprehensive smokefree policy regulations ${ }^{22-24}$. Findings from this research strengthen the urge to protect vulnerable groups from exposure to cigarette smoke as early as possible. It could be achieved, by taking into account the characteristics of families with social vulnerabilities.

\section{Conclusion}

Several conditions representing the more vulnerable family, like more children, shorter birth spacing, younger age of mother and father, and shorter years of father education. Those related to higher at home SHS exposure for infants.Lower cognitive stimulation was found as a factor associated with higher infants' SHS exposure at home, specifically daily and weekly exposure. The high prevalence for infant to exposed with daily SHS exposure need urgent attention for intensive health promotion and consistent implementation of smoke-free legislation to protect infant and breastfeeding mothers from SHS exposure in private space like home. It is recommended to include the message for protecting infants and breastfeeding mothers from SHS exposure at home. Future research is needed to develop a health promotion model to prevent infant SHS exposure at home, such as couple counseling during pregnancy.

\section{Acknowledgment}

The authors would like to thank the Head of Magelang Health Research, Development Center and Public Health Centresin Magelang. We highly appreciate the support and facilities for this research. We also thank the participants for their cooperation and support.

Ethical Clearance: Taken fromThe National Institute of Health Research and Development Ethics Committee, Indonesia(LB.02.01/5.2/KE.163/2016).

Source of Funding: this research supported by National Health Institution for research and Development, Ministry of Health, Indonesia.

Conflict of Interest: The authors confirm that there are no conflicts ofinterest. 


\section{References}

1. Öberg M, Jaakkola M, Woodward A, Peruga A, Prüss-Ustün A. Worldwide burden of disease from exposure to second-hand smoke: A retrospective analysis of data from 192 countries. Lancet. 2011;377(9760):139-46.

2. Faber T, Been J V., Reiss IK, MacKenbach JP, Sheikh A. Smoke-free legislation and child health. npj Prim Care Respir Med [Internet]. 2016;26(April):1-8. Available from: http://dx.doi. org/10.1038/npjpcrm.2016.67

3. Digiacomo SI, Jazayeri MA, Barua RS, Ambrose JA. Environmental tobacco smoke and cardiovascular disease. Int J Environ Res Public Health. 2019;16(1).

4. Flenady V, Koopmans L, Middleton P, Froen JF, Smith GC, Gibbons K. Major risk factors for stillbirth in high-income countries: A systematic review and meta-analysis. Lancet. 2011;377(9774):1331-40.

5. Simons E, To T, Moineddin R, Stieb D, Dell S. Maternal second-hand smoke exposure in pregnancy is associated with childhood asthma development. J Allergy Clin Immunol Pr. 2014;2(2):201-7.

6. Dai S, Chan KC. Associations of household environmental tobacco smoke exposure with respiratory symptoms and utilisation of medical services in healthy young children in Hong Kong. Tob Induc Dis. 2020;18:1-13.

7. Jarvie JA, Malone RE. Children's secondhand smoke exposure in private homes and cars: An ethical analysis. Am J Public Health. 2008;98(12):2140-5.

8. Chassin L, Presson CC, Rose J, Sherman SJ, Davis MJ, Gonzalez JL. Parenting style and smoking-specific parenting practices as predictors of adolescent smoking onset. J Pediatr Psychol. 2005;30(4):333-44.

9. Latifah L, Nurcahyani YD, Yunitawati D, Kusrini I, Mulyantoro DK. Breastfeeding Iodine Level and Infant Development in Replete and Non Replete Iodine Area. Asian Congr Nutr. 2019;

10. Kusrini I, Farebrother J, Mulyantoro DK. Adequately iodized salt is an important strategy to prevent iodine insufficiency in pregnant women living in Central Java, Indonesia. PLoS One [Internet]. 2020;15(11):e0242575. Available from: http://dx.doi.org/10.1371/journal.pone.0242575

11. Yunitawati D, Latifah L. Caregiving Resources and Psychosocial Stimulation Among Infants in Magelang Regency. Adv Heal Sci Res. 2020;22(Ishr 2019):261-7.

12. Mott FL. The Utility of the HOME-SF Scale for Child Development Research in a Large National Longitudinal Survey: The National Longitudinal Survey of Youth 1979 Cohort. Parenting. 2004;4(2):259-70.

13. Petersen AB, Thompson LM, Dadi GB, Tolcha A, Cataldo JK. Factors associated with secondhand tobacco smoke in the home: An exploratory cross-sectional study among women in Aleta Wondo, Ethiopia. BMC Public Health [Internet]. 2016;16(1):1-12. Available from: http://dx.doi org/10.1186/s12889-016-3588-6

14. Mbulo L, Palipudi KM, Andes L, Morton J, Bashir $\mathrm{R}$, Fouad H, et al. Secondhand smoke exposure at home among one billion children in 21 countries: findings from the Global Adult Tobacco Survey (GATS). Tob Control. 2016;25:1-12.

15. Fauzi R, Ma'ruf M, Bonita, Puspawati N, Soewarso K, Antojo A. Hubungan Terpaan Iklan, Promosi, Sponsor Rokok dengan Status Merokok di Indonesia. Vol. 2019. Jakarta;

16. Xie M, Jia C, Zhang Y, Wang B, Qin N, Cao S, et al. Household exposure to secondhand smoke among chinese children: Status, determinants, and co-exposures. Int $\mathrm{J}$ Environ Res Public Health. 2020;17(15):1-12.

17. Baheiraei A, Ghafoori F, Nedjat S, Foroushani AR. Sociodemographic characteristics and secondhand smoke exposure among women. Tanaffos. 2013;12(2):41-7.

18. Sein A, Hitke MT, Sinha D, Kyaing N. Exposure to second-hand tobacco smoke among adults in Myanmar. Indian J Cancer. 2012;49(4):410-8.

19. Arechavala $\mathrm{T}$, Continente $\mathrm{X}$, Pérez-Ríos M, Schiaffino A, Fernández E, López MJ. Sociodemographic factors associated with secondhand smoke exposure and smoking rules in homes with children. Eur J Public Health. 2019;29(5):843 $\square 9$.

20. Jeong W, Kim YK, Joo JH, Jang SI, Park EC. The 
association of smoking exposure at home with attempts to quit smoking and cessation success: A survey of South Korean adolescents who smoke. Int J Environ Res Public Health. 2020;17(11):1-11.

21. Orton S, Jones LL, Cooper S, Lewis S, Coleman T. Predictors of children's secondhand smoke exposure at home: A systematic review and narrative synthesis of the evidence. PLoS One. 2014;9(11).

22. WHO. How can we best protect non-smokers from exposure to tobacco smoke. Copenhagen; 2014.
23. WHO. Global Adult Tobacco Survey (GATS) Vietnam 2015. Hanoi; 2016.

24. Tsai J, Homa DM, Gentzke AS, Mahoney M, Sharapova SR, Sosnoff CS, et al. Morbidity and Mortality Weekly Report Exposure to Secondhand Smoke Among Nonsmokers-United States, 19882014. Morb Mortal Wkly Rep Expo [Internet]. 2018;67(48):1342-6. Available from: https:// wwwn.cdc.gov/nchs/data/nhanes/2013-2014/ manuals/2013 